\title{
Neural Mechanisms Of Attention: The Northern California Years
}

\author{
Robert T. Knight, M.D. \\ Department of Psychology, University of California-Berkeley, \\ 3210 Tolman Hall, Berkeley, CA 94720-1650
}

Simon Brailowsky is best known for his contributions to brain plasticity. Yet, it was a longstanding fascination with the neural mechanisms of attention that occupied the brunt of his scientific inquiries during his three years in California, from 1983 to 1985 . Simon arrived at the University of California-Davis ostensibly to finish his Ph.D. from the University of Paris. He didn't have a firm plan in mind but, in Simon's typical world and scientific view, he knew that something interesting would emerge. We immediately became friends and collaborators and decided to develop an animal model of hemispatial neglect that we could use to assess the behavioral, neuropharmacological, and electrophysiological underpinnings of attention. In retrospect, we may have been a bit overambitious. Nevertheless, and perhaps more important, Simon wanted any rat attention model to be easily transferable to the understanding of human attention dysfunction. Several groups, led by the work of Hillyard and colleagues at the University of California San Diego, had shown that evoked potentials could be used to monitor attention-related neural activity in behaving humans. Simon reasoned that instead of employing single-unit recording in animals, we should develop a rat evoked-potential attention model so that the work would be more easily comparable to the human data. This innate drive to do research that is immediately relevant to human behavior became a central theme of virtually all of Simon's professional work in epilepsy, stroke, and plasticity.

A rat attention model necessitated two parallel lines of research. The first problem was how to induce and measure neglect in animals. Simon came up with the brilliant idea of inducing a reversible behavioral syndrome by the microinfusion of GABA into the putative brain regions of interest. His initial studies in acute cats showed that regional GABA application reliably and reversibly suppressed sensoryevoked potentials from primary sensory cortices, and he reasoned that a similar effect would occur in the motor cortex (Brailowsky \& Knight, 1984; Knight \& Brailowsky, 1990). A small digression provides some insight into the problems and joys of our early acute animal endeavors. We were performing an acute animal experiment on the effects of GABA on the auditory cortex of a cat who was being ventilated by the standard Harvard Pump. At about 2 o'clock in the morning, after about 9 to $10 \mathrm{~h}$ of preparation and initial experimental manipula-tions, the pump froze, along with the hearts of both investigators. Without much discussion, I began disassembling the pump, trying to unfreeze the mechanism. I will never forget Simon sitting there blowing into the tracheostomy tube, keeping the animal ventilated, and intermittently yelling to me in his typical fashion, "Come on man, hurry it up." This went on for seemingly hours but in reality for only a few hilarious minutes before large amounts of oil and brute force unfroze the pump and put us back on track.

The then recent development of the ALZA minipump afforded a possible 7-d GABA infusion period, which could be used to examine the time course of local cortical inactivation. The likely target sites were either parietal or prefrontal regions, on the basis of the extant animal and human neglect literature. We decided, however, that we should first examine motor performance, reasoning that this would be more amenable to 


\begin{tabular}{|c|c|c|c|}
\hline DESCRIPTION & SCALE & $X$ PERCENTAGE & $=\begin{array}{c}\text { TOTAL SCORE } \\
\text { (range) }\end{array}$ \\
\hline $\begin{array}{l}\text { Unable to run } \\
\text { Dragging limb } \\
\text { Falls or }>3 \text { slips } \\
\text { 3 slips and /or } \\
4 \text { toes off beam } \\
\text { (unilaterally) } \\
\text { Hypotonus (limping) } \\
\text { Wider sustentaion } \\
\text { base ( } 4 \text { toes off } \\
\text { beam, bilaterally) } \\
\text { No apparent deficit }\end{array}$ & $\begin{array}{l}6 \\
5 \\
4 \\
3 \\
2 \\
1 \\
0\end{array}$ & $\begin{aligned}(1 & =258 \\
2 & =508 \\
3 & =758 \\
4 & =1008)\end{aligned}$ & $\begin{array}{l}6-24 \\
5-20 \\
4-16 \\
3-12 \\
2-8 \\
1-4 \\
0\end{array}$ \\
\hline
\end{tabular}
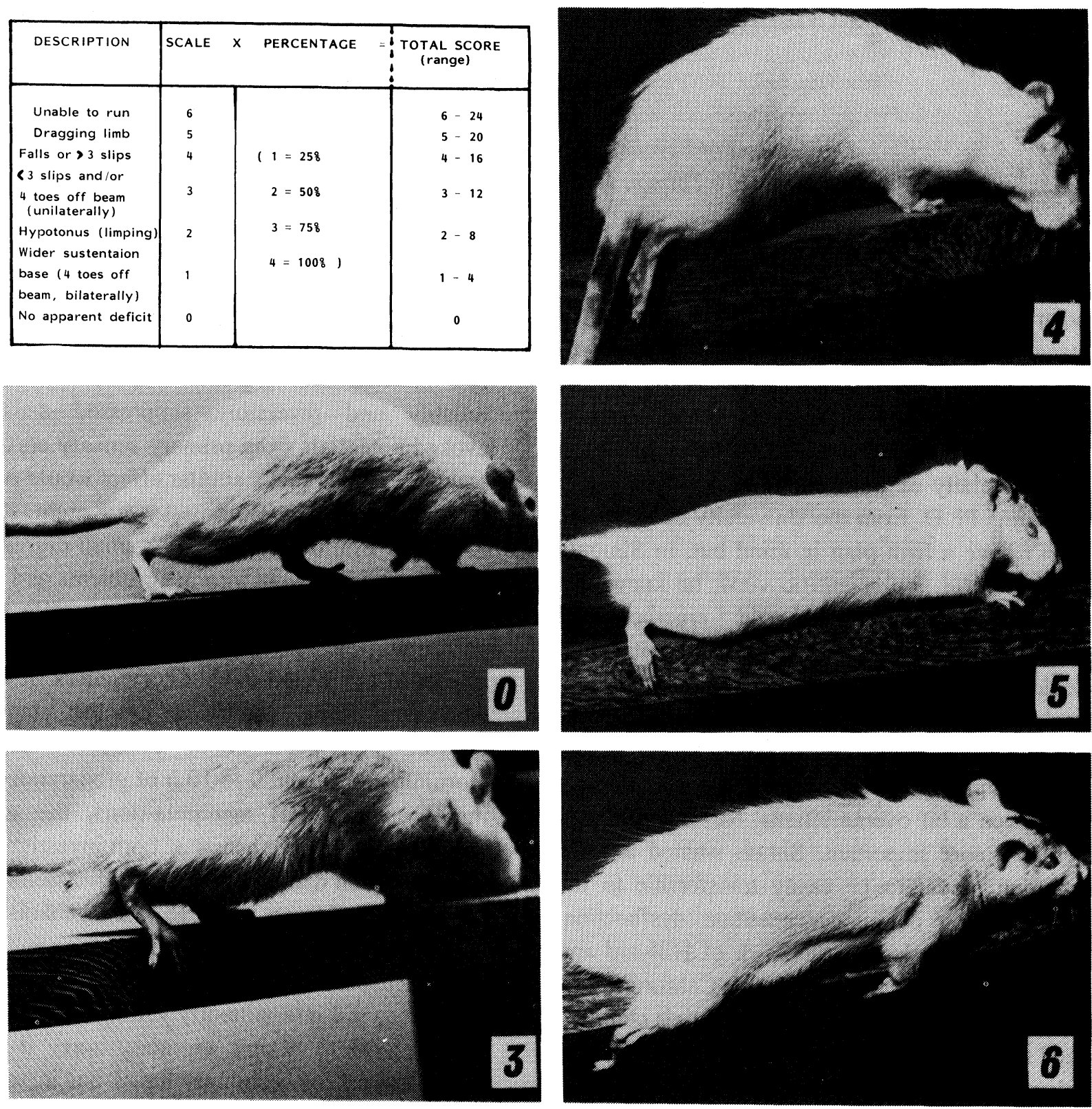

Fig. 1: Scale used for motor behavior quantification. Behaviors 1 (unable to run) and 2 (dragging limb) are not shown in the figure as they are not apparent in a still frame. On the day after initiation of GABA infusion, the animal was unable to run on the beam and rolled over and lay on the side contralateral to the minipump implanted cortex. This behavior rated the maximum deficit score of 6 . An animal received a 5 if it traversed the beam while dragging a hindlimb. A 4 if it fell or traversed the beam slipping off on more than half of its steps, a 3 if it traversed the beam without slipping but with the contralateral hind paw touching the lateral aspect (edge) of the beam, a 2 if the animal limped with one hindlimb (hypotonus) and a 1 if the animal widened its base with the four toes off the beam bilaterally. Motor behavior was quantified over each quarter section of the beam. (from Brailowsky et al., 1986a). 
measurement than attention. Basically, we wanted to validate the idea that regional GABA infusion could produce a reliable neurological deficit. Little did we know that the measurement of motor performance would also be problematic and lead to a diversion from our initial attention interests to the study of hemiparesis. Behavioral research at that time employed the paw print method of measuring motor performance in rats who were subjected to cortical ablations or carotid ligations. The logic of this approach was simple, but the implementation in our hands was comical at best. After lesioning an animal's motor cortex, the experimenter would put ink on the rat's paws and place them on a piece of white paper on the floor of the lab. The rat would then be induced to walk around the lab, and the investigator would follow and mark the degree of splaying of the hindlimbs of the animal. More splaying equaled more motor deficit. Simple but the animals, however, had an unfortunate tendency to circle over their footprints, eventually leading to a confusing mosaic of footprints, reams of inked paper, and two investigators with daily ink-stained hands and no reliable data.

Something new needed to be developed, and Simon revealed his unique experimental talents by developing the beam method for measuring motor performance (Brailowsky et al., 1986a). The method was extremely simple, low cost, and reproducible. The low-cost version was very appealing to Simon because he was a bit concerned about the vicissitudes of funding when he would eventually return to Mexico. The rats were trained to return to their home cage by running along a 2-meter beam. The distance from the home cage was lengthened each day until the animal ran the entire beam. No negative reinforcement was needed and once trained, the rats were ready for the infusion experiments. Simon studied young and old rats with all the appropriate controls of sham infusion and postmortem verification of cannulae damage. GABA infusion produced a robust hemiparesis that was easily quantifiable by a grading system developed by Simon (see Fig. 1). The syndrome lasted 5 days in the young rats and at least 2 months in the old rats, and subsequent experiments revealed an exquisite delayed sensitivity to catecholaminergic manipulations with important clinical implications (Brailowsky et al., 1986b; Brailowsky et al., 1987). We felt that we were on to a potentially important method for stroke research, and to further characterize this novel stroke model, we excitedly prepared our first grant application to the NIH. We found that funding vicissitudes know no borders when the reviews referred to our method as 'medieval' and summarily dismissed our application. Of course, they were wrong, and the Brailowsky beam method is now a standard tool for rodent stroke research laboratories throughout the world. I can't help but wonder where our collaboration might have gone if funding had been obtained, permitting Simon to increase his time in California.

In parallel with the behavioral and pharmacological experiments, we were attempting to develop a reliable method for evoked-potential recording in awake, freely moving rats. This research line also took some unexpected turns. Bob Galambos kindly gave us the sound chamber and equipment used by him and Jewett to discover the brainstem auditory evoked potential. We patched together an auditory sound delivery system and an acceptable amplifier and averaging system. Simon did not want to re-visit previous mistakes in the animal attention literature, in which uncontrolled peripheral factors clouded attentionrelated interpretations of data. This led to a long series of experiments, developing first a rapid, free-field brainstem auditory evoked potential method (BAEP) for daily quantification of auditory sensory thresholds in the rat (Simpson et al., 1985). The technique worked perfectly and allowed us to be sure that any effects we obtained were not due to peripheral factors. We then embarked on a long series of parametric studies delineating all the principle factors effecting the awake rat AEP (Knight et al., 
A.

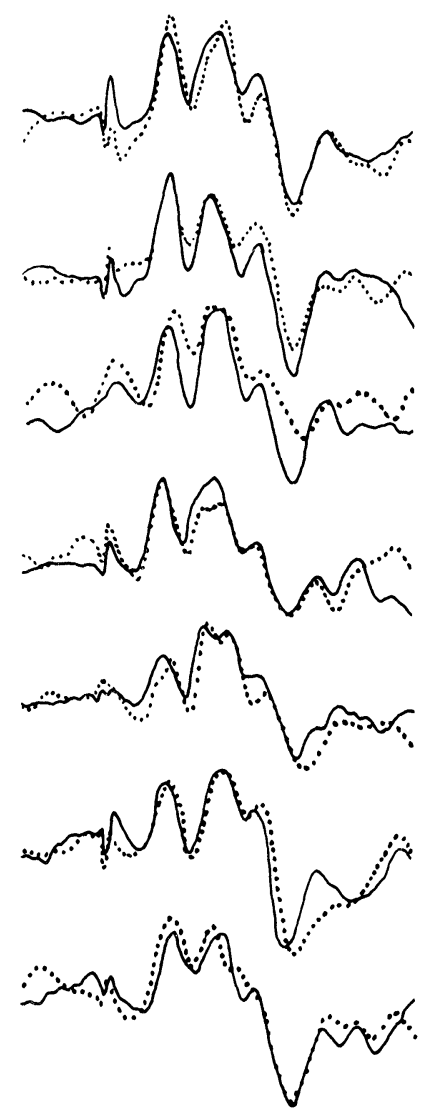

AWAKE

IMMOBILE

GROOMING
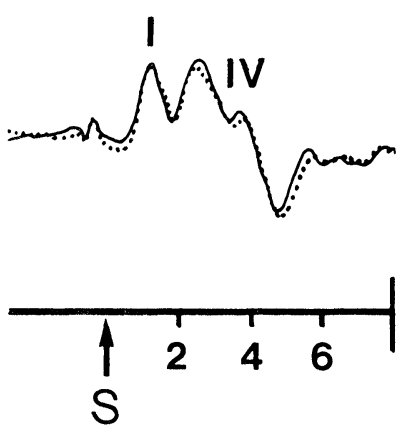

B.

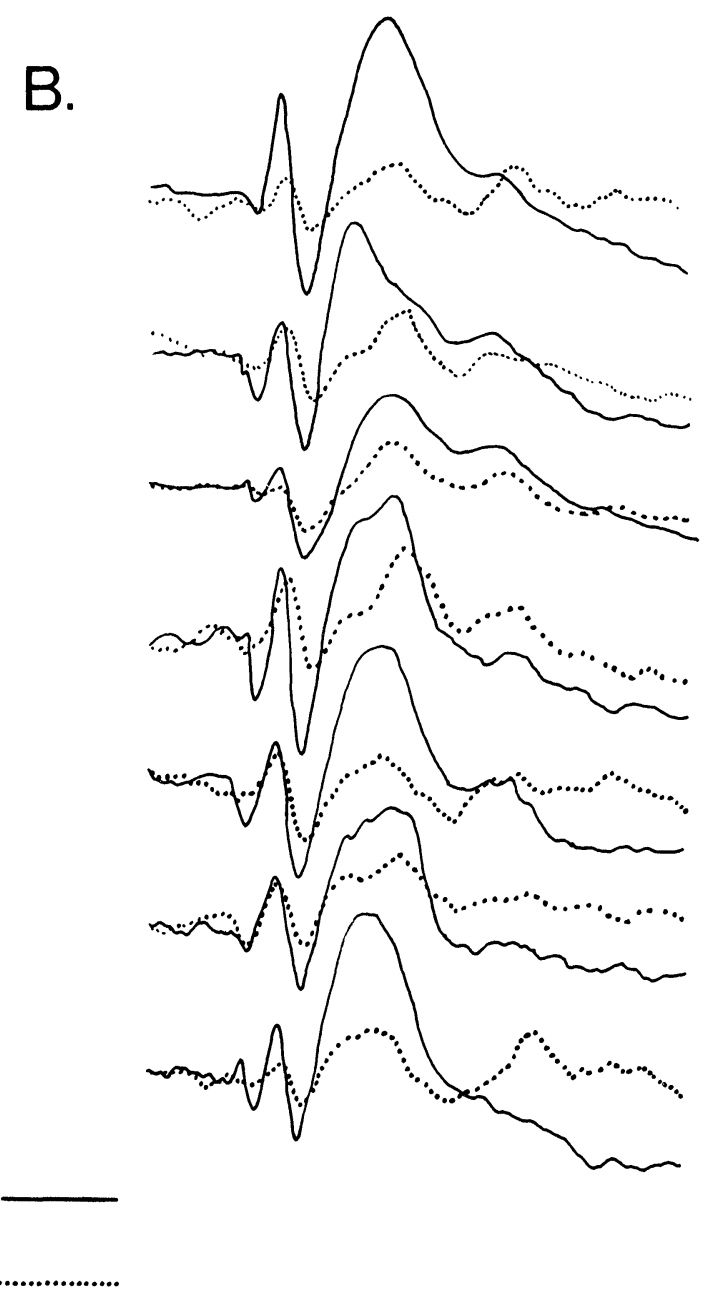

N50

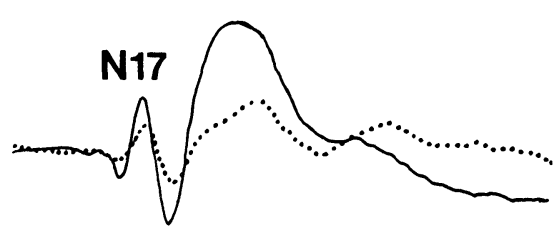

P23

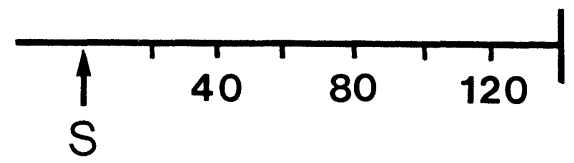

Fig. 2: Simultaneously recorded brain stem auditory evoked potentials (2A) and long latency AEPS (2B) from the rat in the awake state and while grooming. Grooming was defined behaviorally and was associated with prominent theta in the EEG power spectrum. Data from seven animals are shown. The grand average for the group is shown on the bottom. Wave I represents auditory nerve activity and wave IV arises in the inferior colliculus. There is no difference in the BAEPS for the two behavioral states providing a control for peripheral sensory factors. Grooming has prominent effects on long latency hippocampal dependent AEPs with effects onsetting by 15-20 milliseconds post-stimulation. The results provide evidence of early state dependent gating of sensory flow (unpublished data). 
1985). This laid the groundwork for our real questions of interest that focused on the neural mechanisms of attention. We hoped to delineate how sensory flow was regulated in behaving animals. Much data was collected, but our funding expired, Simon had to move on, and the data never made it to submission, with only a small part appearing in abstract form (MenesesOrtega et al., 1993). We both moved on to new research areas, in human attention for me and in neural plasticity and epilepsy for Simon. Sadly, Simon was planning a sabbatical in California in the next year or two years, where we could finish writing up our long dormant AEP/behavioral data and pursue new studies at the University of California-Berkeley, focused on our initial joint interests in attention.

A brief review of our unpublished data seems appropriate. We collected epidural and in some cases, intracerebral AEP data from rats in various behavioral states, including awake, slow wave sleep, REM, grooming, and exploring. All states were quantified by both behavioral observation and power spectrum analysis. Several interesting findings emerged. Perhaps the most interesting to Simon was the observation that the behavioral states that are associated with hippocampal theta, such as REM, exploring, and grooming, were associated with a prominent suppression of the rat AEP onsetting as early as 15 to $20 \mathrm{msec}$ poststimulation (Fig. 2). This effect was clearly not due to some extraneous peripheral factors because the simultaneously recorded BAEP was comparable between awake and theta states in animals who showed marked suppression of longer latency, hippocampal dependent AEPs. This suggested a powerful behavioral state dependent mechanism for the regulation of sensory flow. I think of all the data that we collected, this was by far the most exciting to
Simon because it connected with his abiding interest in attention.

Our relatively brief period of scientific collaboration had all the successes and failures that draw one to a research career. Equally as important, we developed a long-standing friendship that included not only us but also our families. We shared many wonderful times camping and fishing in the mountains. His love of life and science and his deep commitment to his colleagues and friends is sorely missed.

\section{REFERENCES}

Brailowsky S, Knight RT. Inhibitory processes in cat somatosensory cortex: a pharmacological study. Brain Research, 1984; 322: 310-315.

Brailowsky SK, Knight RT, Blood K, Scabini D. GABA induced potentiation of cortical hemiplegia. Brain Research 1986a; 362: 322-330.

Brailowsky S, Knight RT, Efron R. Phenytoin increases the severity of cortical hemiplegia in rats. Brain Research 1986b; 376: 71-77.

Brailowsky S, Knight RT. Recovery from GABAmediated hemiplegia in young and aged rats: Effects of catecholaminergic manipulations. Neurobiology of Aging 1987; 8: 441-447.

Knight RT, Brailowsky S. Auditory evoked potentials from the primary auditory cortex of the cat: topographic and pharmacological studies. Electroencephalography and Clinical Neurophysiology 1990; 77: 225-232.

Knight RT, Brailowsky S, Scabini D, Simpson S. Surface auditory evoked potentials in the unrestrained rat: component definition. Electroencephalogr Clin Neurophysiol 1985; 161: 430-439.

Meneses-Ortega S, Brailowsky S, Knight RT. Changes inauditory evoked potentials during sleep and wakefulness in the rat. Soc Neurosci (Abstract) 1993; 19: 1241.

Simpson G, Knight RT, Brailowsky S, Prospero O, Scabini D. Altered peripheral and brainstem auditory function in aged rats. Brain Res 1985 ; 348: 28-35. 

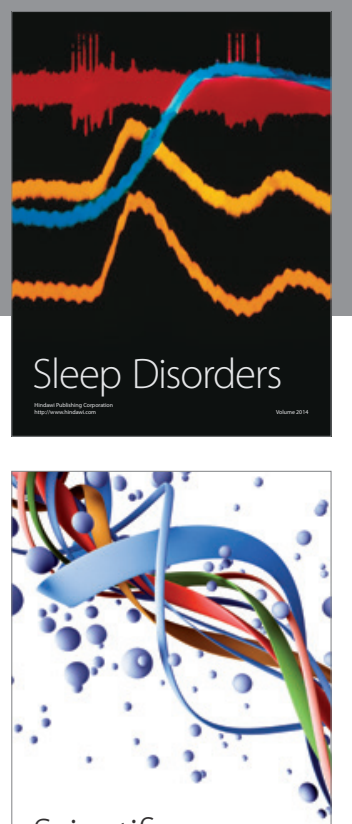

Scientifica
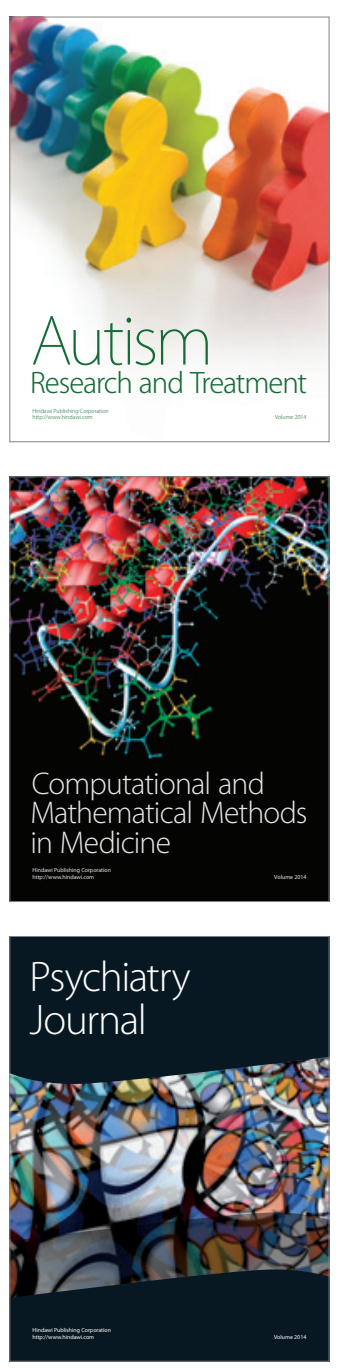
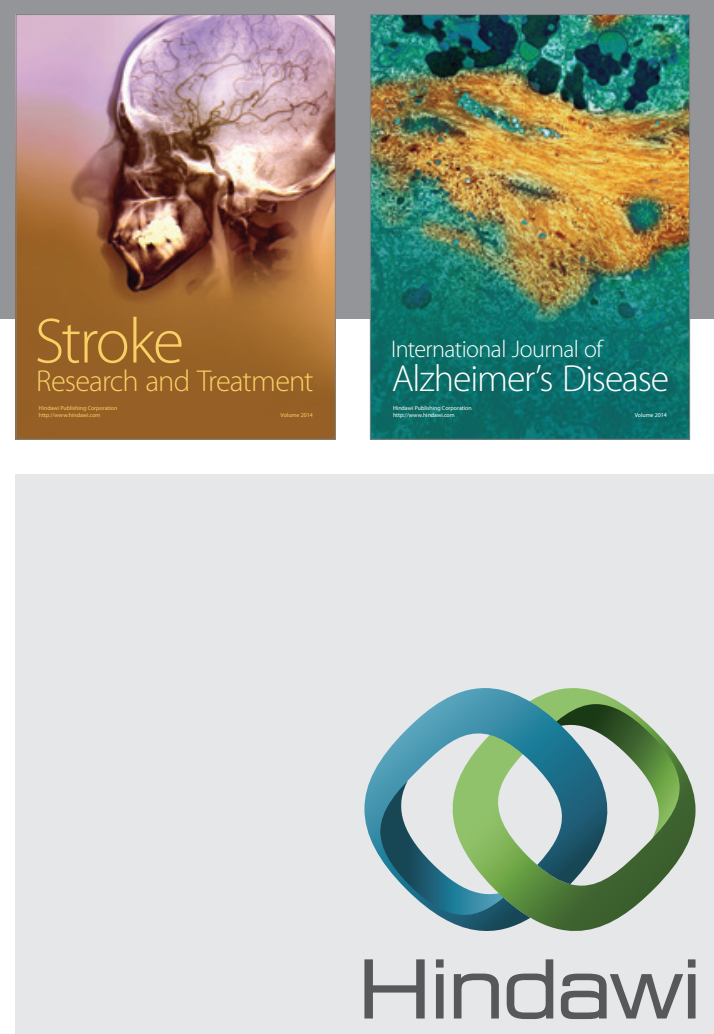

Submit your manuscripts at

http://www.hindawi.com
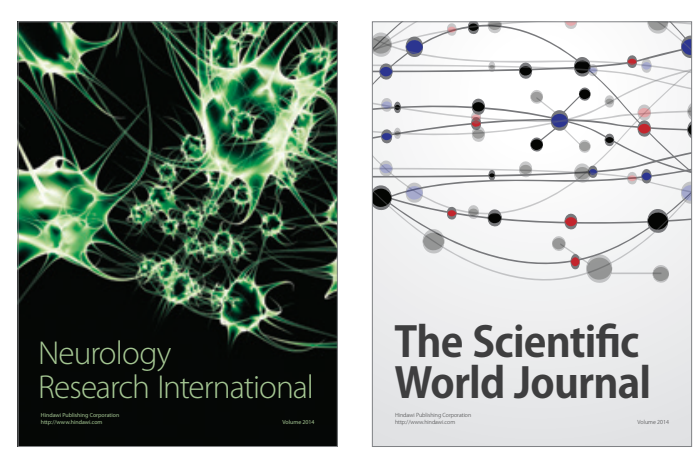

The Scientific World Journal

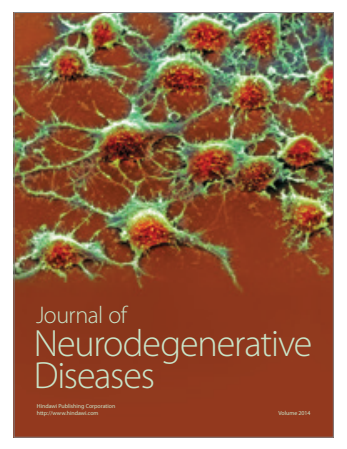

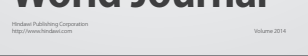

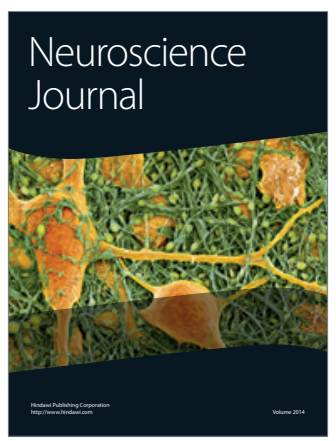

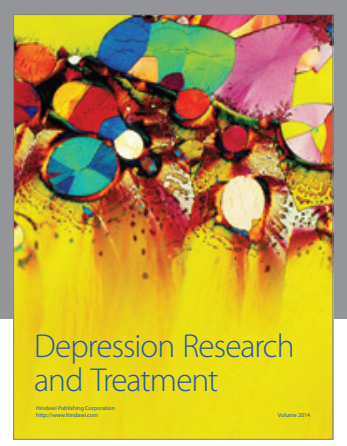
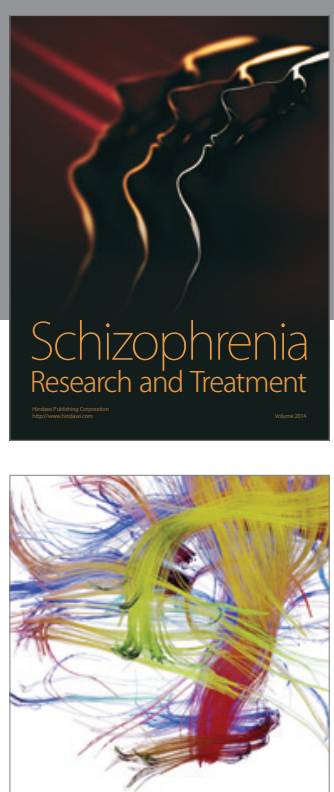

Brain Science

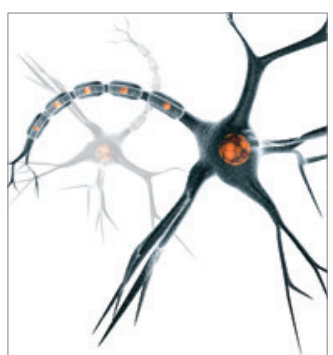

Neural Plasticity
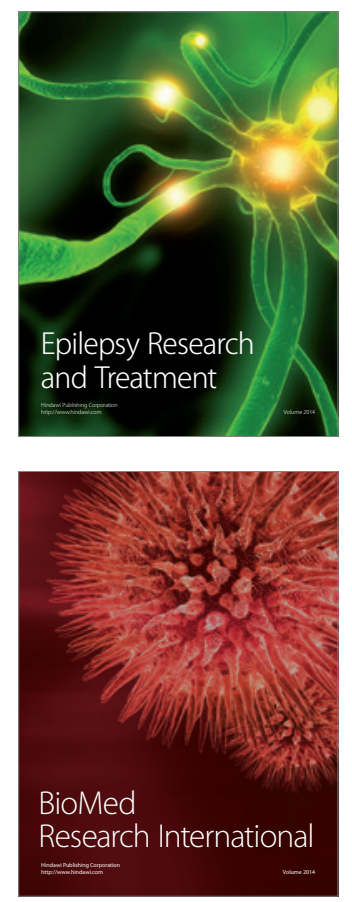

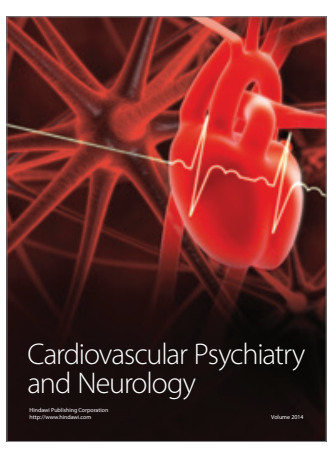

Parkinson's

Disease
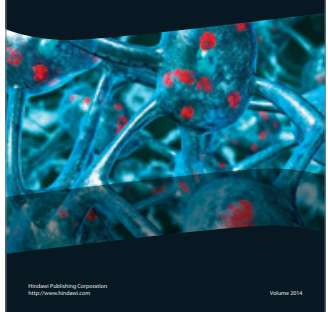